$\begin{array}{ll}\text { Abstracta Iranica } & \begin{array}{l}\text { Abstracta Iranica } \\ \text { Revue bibliographique pour le domaine irano-aryen }\end{array} \\ & \text { Volume } \mathbf{4 0 - 4 1} \mid \mathbf{2 0 1 9} \\ & \text { Comptes rendus des publications de 2017-2018 }\end{array}$

\title{
Javier Alvarez-Mon, “The Elamite artistic heritage
} of Persia"

Anahita Zabeti

\section{(2) OpenEdition}

\section{Journals}

Édition électronique

URL : http://journals.openedition.org/abstractairanica/49912

DOI : 10.4000/abstractairanica.49912

ISBN : 1961-960X

ISSN : 1961-960X

Éditeur :

CNRS (UMR 7528 Mondes iraniens et indiens), Éditions de l'IFRI

Référence électronique

Anahita Zabeti, « Javier Alvarez-Mon, "The Elamite artistic heritage of Persia" », Abstracta Iranica [En ligne], Volume 40-41 | 2019, document 3, mis en ligne le 30 décembre 2019, consulté le 23 avril 2021. URL : http://journals.openedition.org/abstractairanica/49912 ; DOI : https://doi.org/10.4000/ abstractairanica.49912

Ce document a été généré automatiquement le 23 avril 2021

Tous droits réservés 


\title{
Javier Alvarez-Mon, “The Elamite artistic heritage of Persia"
}

\author{
Anahita Zabeti
}

\section{RÉFÉRENCE}

Javier Alvarez-Mon, "The Elamite artistic heritage of Persia" in Javier Alvarez-Mon, Gian Pietro Basello, Yasmina Wicks (eds.). The Elamite world. Londres \& NewYork: Routledge, 2018, p. 829-850.

1 L'A. réexamine l'art achéménide, laissant de côté les deux approches classiques des influences mésopotamienne et grecque, et situe l'art royal dans le contexte d'un héritage élamite sans nier toutefois l'influence des autres cultures.

2 En comparant les arts architecturaux et sculpturaux monumentaux achéménides à Pasargades, à Naqš-e Rostam et à Persépolis aux vestiges élamites, il met en évidence des parallèles artistiques et montre la participation de l'Elam à la formation de l'art achéménide, présent autant dans la structure que dans l'iconographie.

3 Les principes artistiques et idéologiques de base ainsi que des réalisations achéménides trouvent leurs origines dans les traditions artistiques élamites, issue d'un long processus d'acculturation.

4 La prédominance autochtone élamite et l'omniprésence des productions artistiques locales sont des faits évidents dans l'art perse de cette époque. C'est grâce à une capacité pragmatique et au recours aux connaissances héritées des traditions locales que les Achéménides ont su manifester dans l'art un nouveau pouvoir royal et particulièrement la représentation d'un nouvel ordre impérial pour générer un nouveau message universel. 


\section{AUTEURS}

ANAHITA ZABETI

Doctorante EPHE, Mondes iranien et indien, Paris 